\title{
Determination of Alterations in Forest Condition Using Various Measures of Land Use Change along an Urban-Rural Gradient in the West Georgia Piedmont, USA
}

\author{
Diane M. Styers, ${ }^{1,2}$ Arthur H. Chappelka, ${ }^{1}$ and Greg L. Somers ${ }^{1}$ \\ ${ }^{1}$ School of Forestry \& Wildlife Sciences, Auburn University, Auburn, AL 36849-5418, USA \\ ${ }^{2}$ School of Forest Resources, University of Washington, Box 352100, Seattle, WA 98195-2100, USA \\ Correspondence should be addressed to Arthur H. Chappelka, chappah@auburn.edu \\ Received 3 February 2011; Accepted 14 March 2011 \\ Academic Editor: G. Moreno
}

Copyright () 2011 Diane M. Styers et al. This is an open access article distributed under the Creative Commons Attribution License, which permits unrestricted use, distribution, and reproduction in any medium, provided the original work is properly cited.

\begin{abstract}
Our overall goal was to examine forest condition across different land use types through measurement of various biotic, abiotic, and anthropogenic variables. Thirty-six permanent 0.05 -ha circular plots were established along an urban-rural gradient near Columbus, Ga, USA. In general, forest structure did not differ by land use type for the majority of variables measured. However, urban forests contained less total tree and hardwood species than developing or rural areas. Regarding forest condition, no differences were observed for pest or disease incidence by land use, but more mechanical injury (broken branches, wounds, etc.) was found in urban locales. Lichens were the most sensitive indicator of possible changes in forest condition. Lichen incidence, abundance, and species richness were the greatest in rural forests and the least in urban locations. These factors were related to several indicators of urbanization such as housing density and distance from roads. In this case study subtle, but significant changes in forest structure and condition may have resulted from alterations in land use patterns.
\end{abstract}

\section{Introduction}

Urbanization is a leading cause of land transformation worldwide and is occurring rapidly in many regions of the United States as a result of an ever-expanding population base [1]. Urbanization describes a process whereby the portion of a population living in cities increases and land use is transformed into a more human-modified pattern of organization [2]. In sprawling metropolitan areas, development is outpacing population growth and Southern cities are among the most rapidly expanding areas of the country [3]. As a result, forested land in this region is being converted to human-modified urban uses at astonishing rates. As populations continue to rise, the conversion of land from rural to urban will only increase. This conversion of forested lands to highly-modified urban areas poses a major threat to the sustainability of Southern forests [4]. Having few topographic boundaries to curb sprawl, many areas of the Southern US are experiencing similar patterns of change.
Due to these factors, understanding the mechanisms determining the vigor of those remaining forests is becoming more critical. As such, studies quantifying forest condition and relating these to changes in land use in surrounding areas are needed.

Healthy forest ecosystems display a balance among tree growth, mortality, and regeneration, and maintain productivity and resiliency to environmental stress [5]. The study of urbanization effects on forest health (structure, condition, and function) is a relatively new avenue of research, and urbanization is often considered an ecosystem stressor similar to pest and disease outbreaks, adverse weather and climate conditions, and air pollution exposure [5]. Land use changes accompanying rapid and uncontrolled urbanization disrupt ecosystem patterns and processes and can serve as a precursor to environmental degradation, allowing other biotic and abiotic stressors to follow [6].

Changes in forest condition often associated with urban and urbanizing systems include crown dieback, broken tops 
and limbs, higher incidence of pests, diseases, and mechanical injury, and lower incidence and species richness of lichen communities $[4,7-10]$. Pest and disease incidence are related to crown dieback and have been reported as being generally higher in urban forests. These issues are important not only from an ecological standpoint of diminished ecosystem structure and function, but also because aesthetics and other social factors play a role in urban natural areas [11-13].

Urban-rural gradient approaches provide a way to evaluate the effects of human modification of land uses on ecosystem health and environmental stress. Gradients provide a spatial context for the study of forest ecosystem structure and function in a range of land use types and at a variety of scales $[1,14,15]$. By analyzing indicators of compositional, structural, and functional characteristics of forest condition, the status of forests can be quantified and compared to similar neighboring forests, as well as to those in varying locations along a regional gradient $[16,17]$. Being able to quantify changes in the landscape resulting from land use conversion will help answer questions as to the nature of impacts to ecosystems, aiding the modification of land management strategies.

Our goal was to determine forest stand structure and condition along an urban-rural gradient through the measurement of various biotic, abiotic, and anthropogenic variables. The general hypothesis is that urban and rapidly urbanizing landscapes are subject to more stressful conditions than those in rural environments. The current study represents a portion of an overall project examining indicators of ecological health using field and remote sensing data along an urban-rural interface in the West Georgia Piedmont, in the vicinity of Columbus, Ga [18-21]. Specific objectives of this study included: (1) ascertaining the status of forest stand structure and condition across the gradient, (2) utilizing data obtained from forest condition assessments to test for significant differences among variables in urban, developing, and rural land use types over a broad landscape scale, and (3) examining relationships among bioindicator and urbanization variables to provide information regarding forest health and patterns of land use change.

\section{Methods and Materials}

2.1. Study Area. The study area (hereafter referred to as "West Georgia") includes the counties of Muscogee (location of City of Columbus), Harris, and Meriwether in the westcentral Georgia Piedmont, USA. This area represents an urban-rural gradient in terms of land development. Urban expansion around Columbus is limited by Fort Benning (a large US military base) to the south and by the Chattahoochee River to the west; therefore, all development occurs to the north and east of Columbus.

The overall study area contains urban, agricultural (pasture), and forested ecosystems typical of the Southern Piedmont. Much of the land in this area was historically cleared for agriculture, but has since regenerated back to forest following a wave of Depression-era abandonment of fields [22]. The resulting mosaic of forested land in "West Georgia" ranges from natural, pure hardwood stands to intenselymanaged pine plantations. Pine-oak forest communities, typical of the plot locations, are generally located on relatively dry exposed slopes and ridges. For a more detailed description of the gradient and changes in land cover, demographics, and land use history, refer to Styers et al. [21].

2.2. Land Cover and Land Use History. For our purposes, U.S. Census Bureau's Census 2000 geographic definitions of urban landscapes were used [23]. "Urban" areas were defined as having a population $>2500$ people and a population density of at least 386 people $/ \mathrm{km}^{2}$ (city of Columbus, Muscogee County); sites were defined as "developing" (i.e., urbanizing) if population growth between 1990 and 2005 was higher than the national average (19\%), but less than the urban areas (Harris and Muscogee Cos). All other land (Harris and Meriwether Cos) was classified as "rural" [20, 23].

2.3. Plot Selection. To assess the degree and spatial extent of forest ecosystem condition in "West Georgia," 36 permanent 0.05-hectare (ha) circular plots (three plots per site; four sites per land use type-urban, developing, and rural) were installed during the winter of 2004-2005 (see Figure 1). Plots were established using criteria modified from the USDA Forest Inventory and Analysis (FIA) National Program guidelines [24]. The gradient extends approximately 100$\mathrm{km}$ from southwest to northeast and is approximately 75$\mathrm{km}$ in width $[20,21]$. Since other studies for the overall "West Georgia" project [15] were conducted within the riparian areas $[17,25]$, there was a more deliberate selection of specific plot locations. Randomly selected plots were stratified within upland interior (at least $30-\mathrm{m}$ from an edge) pine-oak woodlands containing mature loblolly pine (Pinus taeda L.) and oak (Quercus spp.). Other common tree species included yellow poplar (Liriodendron tulipifera L.), black gum (Nyssa sylvatica Marsh) hickories (Carya spp.), sweetgum (Liquidambar styraciflua L.), and red maple (Acer rubrum L.). See Styers [18] for a complete listing of all tree species recorded. Within each site, individual plots were $\geq 100 \mathrm{~m}$ from each other.

2.4. Plot Measures for Forest Structure. Once established, each plot was initially characterized in winter/spring 2005 (see Table 1 for definitions of each of the variables). Within each plot, species and the diameter at breast height $(\mathrm{dbh})$ for each tree were recorded. Total number of trees, percentage of hardwoods, percentage of pines, total number of tree species, and basal area $\left(\mathrm{m}^{2} \mathrm{ha}^{-1}\right)$ were then calculated. Where applicable, the variable values are reported on a per hectare basis.

A total count of all understory trees $(2.5-10 \mathrm{~cm} \mathrm{dbh})$ was determined. Numbers of saplings and shrubs $0.6-2.5 \mathrm{~cm}$ diameter (at ground-level) and at least $1 \mathrm{~m}$ in height were tallied and averaged to the plot-level by recording counts along three transects across the plot area. Groundcover data were recorded as percentages of woody stems, herbaceous plants, leaf litter, and bare ground within five $0.25-\mathrm{m}^{2}$ subplots averaged to plot-level. A count of seedling numbers 
TABLe 1: Definitions for each of the variables measured in "West Georgia".

Variables

Total number of trees $>10 \mathrm{~cm} \mathrm{dbh/ha}$

Total number of hardwoods/ha

Total number of pines/ha

Hardwood : pine ratio

Total number of tree species

Mean $\mathrm{dbh}(\mathrm{cm})$ of all mature trees

Basal area $\left(\mathrm{m}^{2} / \mathrm{ha}\right)$

Median age of stand

$\%$ Peak canopy cover

Mean upper canopy height $(\mathrm{m})$

Mean subcanopy height (m)

Total number of trees $2.5-10 \mathrm{~cm} \mathrm{dbh/ha}$

Mean number of saplings and shrubs $0.635-2.5 \mathrm{~cm} / \mathrm{ha}$

Mean number of seedlings $<0.635 \mathrm{~cm} / \mathrm{ha}$

\% Woody stems/ha

$\%$ Herbaceous plants/ha

$\%$ Leaf litter/ha

$\%$ Bare ground/ha

$\%$ Trees with insect injury

$\%$ Trees with disease injury

$\%$ Trees with mechanical damage injury

$\%$ Insect + disease + mech damage for all trees

$\%$ Trees with lichens

Mean number of lichen species per tree

Mean lichen abundance rank for all hardwoods

Mean number of crustose lichen species on water oaks

Mean number of foliose lichen species on water oaks

Crustose : foliose ratio (on water oaks)

Mean lichen abundance rank for water oaks

Mean dominance of crustose over foliose (on water oaks)

Population density

Housing density

Road density

Plot distance to any road (m)

Plot distance to major road (m)

$\%$ forest

$\%$ pasture

$\%$ grasses (pasture + lawn)

$\%$ urban

$\%$ nonvegetated land (urban + bare ground)

Forest patch density
Definitions

Total number of mature trees $(>10 \mathrm{~cm} \mathrm{dbh}$ ) per hectare (ha)

Total number of mature hardwoods $(>10 \mathrm{~cm} \mathrm{dbh})$ per ha

Total number of mature pines $(>10 \mathrm{~cm} \mathrm{dbh})$ per ha

Ratio of hardwood to pine trees per ha

Total number of different tree species measured at each site

Mean $\mathrm{dbh}$ (in $\mathrm{cm}$ ) of all mature trees $(>10 \mathrm{~cm})$ measured

Basal area $\left(\mathrm{m}^{2} / \mathrm{ha}\right)$

Median age of forest stand as measured by six dominant pines at each site peak canopy cover percentage at each site (measured in mid-June)

Mean height of upper canopy at each site (measured by six dominant trees in main canopy)

Mean height of subcanopy at each site (measured by six average trees in secondary canopy)

Total number of trees $(2.5-10 \mathrm{~cm} \mathrm{dbh})$ per ha

Mean number of saplings and shrubs $(0.635-2.5 \mathrm{~cm}$ diameter and at least $1 \mathrm{~m}$ in height) per ha

Mean number of seedlings ( $<0.635 \mathrm{~cm}$ diameter and $<1 \mathrm{~m}$ in height $)$ per ha

Percentage of groundcover occupied by small woody stems $(<0.635 \mathrm{~cm}$ diameter) per ha

Percentage of groundcover occupied by herbaceous plants per ha

Percentage of groundcover occupied by leaf litter per ha

Percentage of groundcover occupied by bare ground (or dirt) per ha

Percentage of trees with evidence of insect injury

Percentage of trees with evidence of disease injury

Percentage of trees with evidence of mechanical injury

Percentage of trees with evidence of insect, disease, and/or mechanical injury

Percentage of trees with lichen incidence (presence versus absence)

Mean number of lichen species per tree

Mean lichen abundance rank for all hardwoods (percentage of cover: $1=0 \%$; $2=1-20 \% ; 3=21-40 \% ; 4=41-60 \% ; 5=61-80 \% ; 6=81-100 \%)$

Mean number of crustose lichen species per tree

Mean number of foliose lichen species per tree

Ratio of crustose to foliose lichen species per tree

Mean lichen abundance rank for water oaks (percentage of cover: $1=0 \% ; 2=$ $1-20 \% ; 3=21-40 \% ; 4=41-60 \% ; 5=61-80 \% ; 6=81-100 \%)$

Mean dominance of crustose over foliose lichens ( $1=$ crustose; 2 = foliose)

Population density (number of people $/ \mathrm{km}^{2}$ ) for census tract containing site

Housing density (number of houses $/ \mathrm{km}^{2}$ ) for census tract containing site

Road density (length of road in $\mathrm{km} / \mathrm{km}^{2}$ ) for census tract containing site

Measure of distance (in $\mathrm{m}$ ) from each plot to the nearest road

Measure of distance (in $\mathrm{m}$ ) from each plot to the nearest paved road

Percentage of forest cover for census tract containing site

Percentage of pasture cover for census tract containing site

Percentage of grass cover (pasture and urban lawn) for census tract containing site

Percentage of urban/built-up land cover for census tract containing site

Percentage ofurban/built-up land and bare ground (dirt) cover for census tract containing site

Number of forest patches per 100 ha within census tract containing site 
Table 1: Continued.

\begin{tabular}{ll}
\hline Variables & Definitions \\
\hline Forest edge density & Total length of forest edge (in $\mathrm{m} / \mathrm{ha})$ within census tract containing site \\
Forest perimeter-area fractal shape & $\begin{array}{l}\text { Forest patch shape complexity, ranging from simple (1) to complex }(2) \\
\text { perimeter shapes }\end{array}$ \\
Shannon's landscape diversity index & $\begin{array}{l}\text { Proportion of landscape occupied by a patch type of a particular class, where } \\
0=\text { only one patch type,increasing as the number of different patch types } \\
\text { increases }\end{array}$ \\
& $\begin{array}{l}\text { Evenness of areal distribution among patch types, where } 0=\text { uneven areal } \\
\text { distribution or dominance of only one patch type, increasing toward } 1, \text { where }\end{array}$ \\
Shannon's landscape evenness index & there is perfect evenness \\
Maximum seasonal ozone concentration & Maximum ozone concentration measured at site from May-Sept, 2006 \\
Maximum seasonal $\mathrm{NO}_{x}$ concentration & Maximum $\mathrm{NO}_{x}$ concentration measured at site from May-Sept, 2006
\end{tabular}

$(<0.635 \mathrm{~cm}$ diameter and $<1 \mathrm{~m}$ in height $)$ within each of these subplots was also noted and averaged per plot. Plotbased metrics we calculated included age using tree cores from dominant loblolly pine specimens (largest trees per plot), total height (clinometer-derived heights averaged from three each of the dominant pine and hardwood specimens), canopy height to the base of the live crown (using the same criteria as above), and mean percent peak canopy cover (measured in June, at the peak of the growing season) using a moosehorn canopy cover scope (provided by Dr. B. Boyd, Auburn University) derived from three randomly selected points within each plot during mid-June 2005. The average age of the dominant trees and stand basal area were 46, 41, and 50 years and 36,30, and $33 \mathrm{~m}^{2} \mathrm{ha}^{-1}$ for the urban, developing and rural sites, respectively. A more detailed description of stand characteristics including soil series, relative stand age, basal area, peak canopy cover, and the percent hardwood composition per plot and land use (urban, developing, rural) are provided in Styers and Chappelka [19].

2.5. Bioindicator Measures for Forest Condition. Tree condition data collected within each plot included percent pest (e.g., bark beetles, tent caterpillars, oakworms), disease (e.g., galls, cankers, dieback, fusiform rust), and mechanical injury to all trees (wounds, broken limbs, etc.), as well as the combined amount of injury from all three of these factors. Each tree per plot was examined visually based on the USDA Forest Service [24] criteria and incidence of each factor recorded.

Lichens present on trees were also assessed and quantified using a modified system originally designed by the FIA Program [24]. Using this system, a field crew can assign rating scores for relative lichen incidence (percentage of the total number of trees per plot having lichens present), abundance (categorical percentage of lichen cover on tree bole and branches; see Table 1 for categorical divisions), and species richness (number of lichen species present on each individual tree). Lichen incidence and abundance surveys were conducted on all mature $(>10-\mathrm{cm} \mathrm{dbh})$ woody plants above $0.5 \mathrm{~m}$ from the base of the tree within each of the $(0.05$ ha) circular "main" plots [24]. The size of the lichen survey plots was adjusted from FIA Protocol (0.378-ha plot) such that these data would coincide with other data collected from these plots.

Since lichens are known to be very sensitive indicators of ecosystem health [26-28], more detailed data were collected from a single tree species to reduce variability. A $20-\mathrm{cm}$ by 50 -cm grid $\left(1,000-\mathrm{cm}^{2}\right)$ was installed in September 2005 on two water oak (Q. nigra L.) specimens approximately $10-\mathrm{cm}$ to $15-\mathrm{cm}$ dbh within each plot. Each grid was centered on the northeast side of each tree at approximately breast height $(1.55-\mathrm{m})$. Numbers of crustose and foliose lichen species were noted, as was total percent cover (abundance), and which of the two lichen types was dominant within each grid quadrant $(10-\mathrm{cm}$ by $25-\mathrm{cm})$. Fruticose lichens were not measured as part of this project, as this form of lichen was not readily observed on the boles of water oaks. Data from each of the four grid quadrants were then averaged for each tree, and data from the two trees were averaged to represent a single plot value. This procedure was repeated after 12 months, in September 2006, to detect any changes over the course of one year.

2.6. Urbanization Metrics for Predicting Forest Condition. Land cover and landscape pattern data were used to calculate urbanization metrics across the landscape of "West Georgia." The land cover classification system used was modified from Styers et al. [20] to include the following variables: urban/built-up, bare ground, pasture, urban lawn, urban vegetation, deciduous forest, evergreen forest, and water/wetlands. Landscape pattern data were calculated using the 2005 land cover classification as input into Fragstats [29] resulting in the following landscape pattern variables: forest patch density (FORPD), forest edge density (FORED), forest perimeter-area fractal dimension (PAFRAC), Landscape Shannon's Diversity Index (SHDI), and Landscape Shannon's Evenness Index (SHEI).

The urbanization metrics used were population, housing, and road densities, plot distances to any road and nearest major road, percentage of land cover occupied by forest (urban vegetation + deciduous forest + evergreen forest), pasture, grass (pasture + urban lawn), urban/built-up, and nonvegetated land (urban/built-up + bare ground), forest patch and edge densities, forest perimeter-area fractal shape, landscape Shannon's diversity and evenness indices, and 


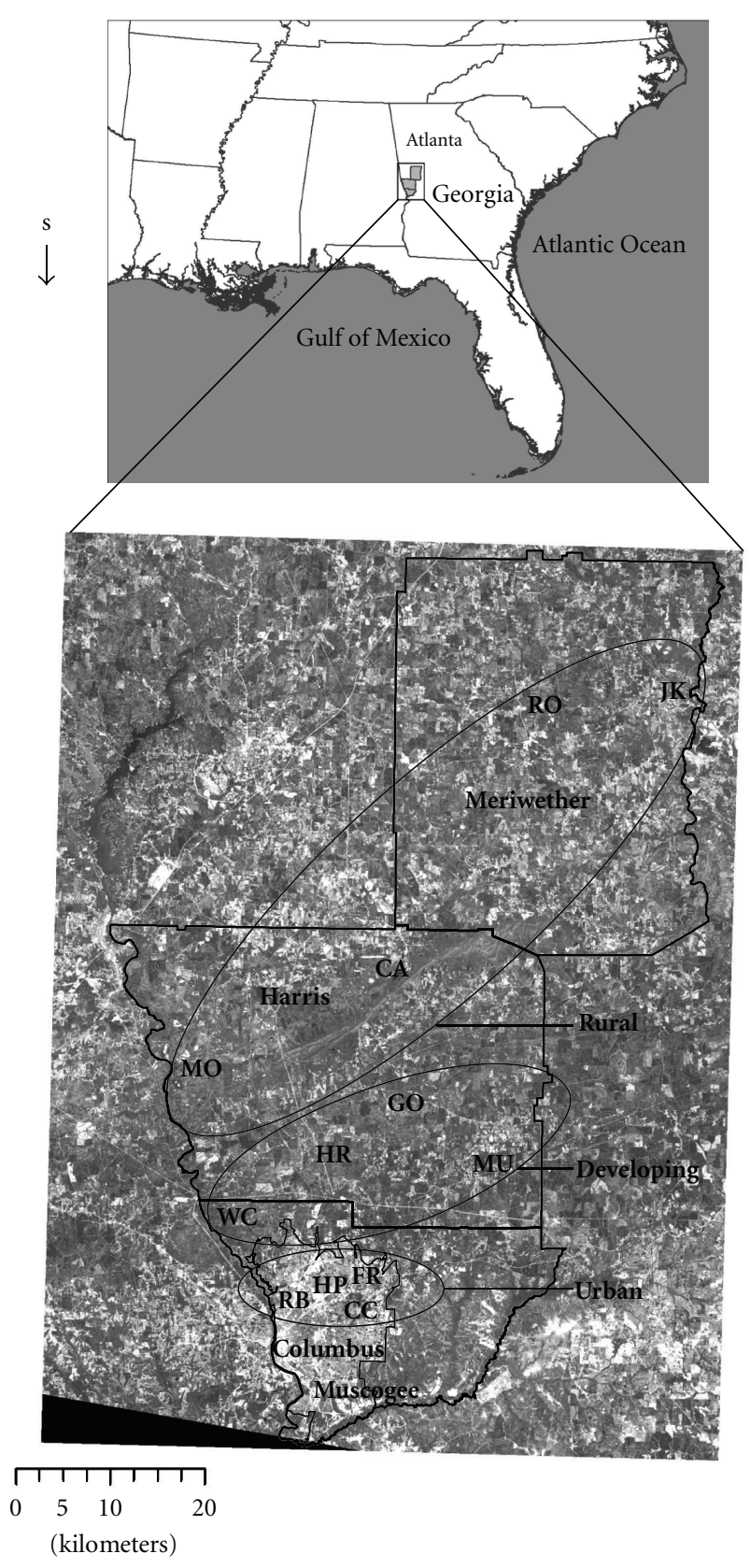

Figure 1: Map of the West Georgia study area showing plot locations and land use designations. Urban Sites: RB:Roaring Branch, HP: Heath Park, CC: Cooper Creek, FR: Flat Rock, Developing Sites: WC: Whiskey Creek, HR: Hunter Road, GO: Goolsby, MU: Mulberry Creek, Rural Sites: MO: Mountain Oak, CA: Callaway, RO: Red Oak: JK: Joe Kurz WMA.

maximum seasonal ozone $\left(\mathrm{O}_{3}\right)$ and nitrogen oxide $\left(\mathrm{NO}_{x}\right)$ concentrations (indicators of potential air pollution stress; refer to Styers and Chappelka [19]).

2.7. Experimental Design and Statistical Analysis. Forest condition variables were obtained from incidence surveys and quantified using a system modified from FIA Program guidelines [24]. A total of 47 forest condition (30) and urbanization (17) variables were extracted from these data and were summed, averaged, and/or combined from the plotlevel to represent data for each of the 12 sites for use in data analysis (Table 1).

Initially, several exploratory analyses were conducted to better understand the data. First, distributions and descriptive statistics for each variable were examined for the 12 sites (averaged from the 36 plots -3 each site) using JMP IN 5.1.2 [30]. Since these means were calculated using data from three plots, they each displayed approximately normal distributions. This allowed the variables to be used without transformation in analyses. Next, variances between plots and sites for each land use type were examined. Since variances between plots and sites were approximately the same for all land use types, then the assumption of equal variances inherent in the one-way analysis of variance (ANOVA) is valid. Further, variances between plots and sites were examined to determine if the study was designed efficiently.

Following these preliminary explorations of the data, ANOVA was performed to test if land-use type significantly affected any of the forest condition variables. We set the $P$ value set at $P<.10$ due to the inherent variability in field studies. Group means were then compared using TukeyKramer HSD, which is a test that controls for the overall error rate by adjusting for multiple comparisons based on all differences among the means.

The next data analysis step was to develop a multivariate correlation matrix (as a data reduction technique) to determine which of the potential predictor variables were highly correlated with one another. Many of these variables displayed multicollinearity and were thus dropped from further analyses. Those shown to be independent amongst one another and that displayed potential to predict lichen incidence (the percentage of trees with lichens; Model 1) or lichen species richness (the number of lichen species per tree; Model 2) were selected as independent variables for use in the regression models. The selection of these two independent variables is discussed in more detail below.

Since several of the lichen indices were correlated with many of the biological, urbanization, and landscape pattern variables, two of these ("percentage of trees with lichens" and "mean number of lichen species per tree") were selected as dependent variables for the regression modeling. These variables were selected because of the relative ease of data collection and lichen presence on all hardwood species. The mean lichen abundance rank was not selected for inclusion in the model because of the large range in categorical values $(1-20 \%, 21-40 \%$, etc.). Variables measured on only water oaks were limited in their ability to predict lichen coverage for forest stands in which water oaks were not present and therefore were also not used. For our purposes, "percentage of trees with lichens," or lichen incidence, is defined as the percentage of the total number of trees per plot having lichens present, while "mean number of lichen species per tree," or species richness, is defined as the mean number of lichen species present on each individual hardwood tree.

The objective of the first regression model was to predict lichen incidence as measured by the percentage of forest hardwood trees having lichens present. The second regression model was created to pre dict lichen species richness as 
measured by the number of lichen species present on each individual hardwood tree. The decision to use lichens as surrogates for forest condition was also based on numerous reports indicating lichens are good bioindicators of forest health, specifically relating to air pollution exposure $[7,10$, 26] and edge effects resulting from forest fragmentation, or urbanization [31-33]. Different combinations of variables were used to develop eight different scenarios for this part of the analysis. All variables collected were initially used as input into the model regardless of their significant difference between land use types, because each of these has potential to affect lichen incidence and species richness. Stepwise regression modeling was conducted first for data reduction and significant variable selection, followed by standard least squares using the selected variables to predict lichen incidence (Model 1) and lichen species richness (Model 2).

\section{Results}

3.1. Exploratory Analysis (ANOVA). With respect to forest structure, only 2 of the 18 variables examined were statistically significant (Table 2). The "number of hardwoods" was 1.6- and 1.5x greater in developing and rural locations, respectively, than in urban areas, the "number of tree species" was 1.7- and 1.4-fold greater in developing and rural areas, respectively, than in urban areas.

Regarding "percent pest incidence for all trees" and "percent disease incidence for all trees," there were no significant differences observed between the land use types (Table 3). The "percent mechanical injury incidence to all trees" variable was $2.2 \mathrm{X}$ greater in urban areas than that in rural land use types, while injury in developing areas was not significantly different from either (Table 4). Similarly, the combined injury to trees resulting from pest + disease + mechanical injury was 2.3-fold greater in urban areas than that in rural land use types, while injury to trees in developing areas was not significantly different from either.

"Percentage of trees with lichens" (lichen incidence) in rural areas was 1.7-fold greater than in urban land use types (Table 3). No differences were observed between developing areas and the other land use types. Given the difference in "percentage of trees with lichens" in urban versus rural land use types, and since lichens are known to be very sensitive indicators of ecosystem health [24-26], this variable was used as the independent variable for regression Model 1. The "mean number of lichen species per tree" (lichen species richness) was 4.2- and 3.3X greater in rural and developing land uses, respectively, than that in urban areas. As for Model 1 , due to these observed differences, "mean number lichen species per tree" was used as the independent variable for regression Model 2. "Mean lichen abundance rank (for all hardwoods)" (lichen abundance) was 3.8- and 3-fold greater in rural and developing areas, respectively, than in urban areas.

Additional lichen data were collected from the water oak trees within each plot indicated "mean number of foliose species" was 2.6X greater in rural land use types than in developing areas, while no differences were observed between urban areas and the other land use types. There were no significant differences observed between the land use types in any of the other lichen variables measured (Table 3 ).

Many urban ecological studies have used the percentage of impervious surfaces within a given area as a predictor variable in regression models [15, 17, 25]. However, we believe that there may be other urban-based variables that can better predict forest condition, at least for this study. As such, a diverse assortment of 17 "urbanization" variables was calculated to discern the best potential predictors ( $\mathrm{X}$ variables) of forest condition (Table 4 ). In all but 4 of the 17 variables, there were highly significant differences in urban versus rural land use types (see Table 4).

3.2. Correlation Matrix and Regression Modeling. As shown in Table 5, variables positively correlated with lichen incidence included percent canopy cover and distance to nearest road, while those negatively correlated were upper canopy height, basal area, housing density, dbh, forest edge density, and total percent injury to trees (pest + disease + mechanical), as shown in Table 5. Lichen species richness was positively correlated with distance to nearest road, percent pasture land cover, percent canopy cover, and percent forest land cover, while those negatively correlated included housing density, subcanopy height, forest edge density, percent total nonvegetated land cover, basal area, and $\mathrm{dbh}$ (Table 5).

Based on the findings from the correlation matrix, regression models were then developed. The first model objective was developed to predict lichen incidence as measured by the percentage of forest hardwood trees with lichens present. Only the most robust lichen incidence model will be discussed. Independent variables entered into the model by the mixed stepwise fit procedure were upper canopy height, housing density, dbh, forest edge density, and total percent injury to trees (pest + disease + mechanical). These variables were the best indicators of lichen incidence in "West Georgia" forests, resulting in the following model:

$$
\begin{aligned}
y= & 63.620368-2.239278 \text { total canopy height } \\
& +1.3165475 \text { mean dbh }-0.310389 \text { housing density } \\
& -0.292817 \% \text { I }+\mathrm{D}+\mathrm{M} \text { injury } \\
& +0.8843282 \text { forest edge density. }
\end{aligned}
$$

Housing density alone accounted for $46 \%$ of the variance in the data, with forest edge density adding another $12 \%$ and total height adding another 9\%. The remaining two variables accounted for another $6 \%$ for a total estimated $r^{2}$ of 0.73 . Once the standard least squares regression model was run, these estimates proved to be accurate $\left(r^{2}\right.$ of 0.73 , RMSE $=$ 17.61). The model indicates that lichen incidence may be related to housing density, canopy height, forest edge, and tree dbh.

The second regression model predicted lichen species richness as measured by the number of lichen species present per forest hardwood tree. Again, different combinations of variables were used to develop eight different scenarios for 
TABLE 2: Standard ANOVA values and means $( \pm \mathrm{SE})$ for forest stand structure variables collected in "West Georgia"

\begin{tabular}{|c|c|c|c|c|c|c|c|c|}
\hline \multirow[b]{2}{*}{ Variable } & \multicolumn{2}{|c|}{ Standard ANOVA } & \multicolumn{5}{|c|}{ Tukey-Kramer HSD Comparisons } & \\
\hline & $\begin{array}{l}\text { Mean } \\
\text { Square }\end{array}$ & Prob $>F$ & $\begin{array}{c}\text { Urban } \\
(n=4)\end{array}$ & & $\begin{array}{c}\text { Developing } \\
(n=4)\end{array}$ & & $\begin{array}{c}\text { Rural } \\
(n=4)\end{array}$ & \\
\hline Total number of trees $>10 \mathrm{~cm}$ dbh ha & 19048 & 0.37 & $391.67 \pm 75.69$ & & $523.33 \pm 42.60$ & & $493.33 \pm 72.75$ & \\
\hline Total number of hardwoods /ha & 29448 & 0.04 & $265.00 \pm 56.53$ & (a) & $430.00 \pm 33.17$ & (b) & $388.33 \pm 15.96$ & $(\mathrm{a}, \mathrm{b})$ \\
\hline Total number of pines /ha & 6100 & 0.51 & $126.67 \pm 23.73$ & & $63.58 \pm 27.63$ & & $135.00 \pm 70.52$ & \\
\hline Hardwood: Pine ratio & 7578 & 0.28 & $2.90 \pm 0.26$ & & $89.59 \pm 52.28$ & & $53.12 \pm 33.40$ & \\
\hline Total number of tree species & 11.19 & 0.04 & $4.67 \pm 0.54$ & (a) & $8.00 \pm 1.03$ & (b) & $6.58 \pm 0.58$ & $(\mathrm{a}, \mathrm{b})$ \\
\hline Mean dbh $(\mathrm{cm})$ of all mature trees & 77.78 & 0.07 & $31.33 \pm 3.00$ & & $23.25 \pm 1.29$ & & $24.22 \pm 2.21$ & \\
\hline Basal Area $\left(\mathrm{m}^{2} / \mathrm{ha}\right)$ & 35.68 & 0.41 & $36.09 \pm 3.29$ & & $30.12 \pm 3.85$ & & $32.86 \pm 1.27$ & \\
\hline Median age of stand & 87.74 & 0.36 & $45.81 \pm 4.39$ & & $40.71 \pm 4.15$ & & $50.06 \pm 4.49$ & \\
\hline \% Peak canopy cover & 135.83 & 0.15 & $82.28 \pm 6.02$ & & $91.00 \pm 2.16$ & & $93.33 \pm 1.16$ & \\
\hline Mean upper canopy height (m) & 2.31 & 0.92 & $26.53 \pm 2.05$ & & $25.27 \pm 3.47$ & & $25.16 \pm 2.13$ & \\
\hline Mean subcanopy height (m) & 7.46 & 0.44 & $18.46 \pm 1.70$ & & $16.56 \pm 1.45$ & & $15.82 \pm 1.07$ & \\
\hline Total number of trees $2.5-10 \mathrm{~cm} \mathrm{dbh}$ & 415969 & 0.14 & $244.17 \pm 161.80$ & & $875.00 \pm 281.60$ & & $675.83 \pm 148.92$ & \\
\hline Mean number of saplings $0.635-2.5 \mathrm{~cm}$ & 595.47 & 0.41 & $30.56 \pm 16.76$ & & $31.67 \pm 12.62$ & & $52.22 \pm 4.30$ & \\
\hline Mean number of seedlings $<0.635 \mathrm{~cm}$ & 4.84 & 0.47 & $1.80 \pm 0.85$ & & $3.33 \pm 0.98$ & & $3.93 \pm 1.64$ & \\
\hline$\%$ Woody stems/ha & 0.11 & 0.56 & $0.40 \pm 0.18$ & & $0.64 \pm 0.23$ & & $0.71 \pm 0.20$ & \\
\hline$\%$ Herbaceous plants/ha & 124.92 & 0.29 & $16.38 \pm 5.78$ & & $6.15 \pm 1.94$ & & $7.38 \pm 5.36$ & \\
\hline$\%$ Leaf litter/ha & 34.01 & 0.77 & $88.83 \pm 6.01$ & & $90.17 \pm 7.10$ & & $94.42 \pm 3.07$ & \\
\hline$\%$ Bare ground/ha & 33.54 & 0.58 & $3.79 \pm 2.97$ & & $7.92 \pm 5.82$ & & $2.33 \pm 1.01$ & \\
\hline
\end{tabular}

${ }^{1} \mathrm{SE}=$ standard error of the mean; $n=$ number of study sites sampled; Mean values in a row with different letters are significantly different $(P<.05)$ based on Tukey-adjusted least squares means.

TABLE 3: Standard ANOVA values and means ( \pm SE) for forest condition variables collected in "West Georgia".

\begin{tabular}{|c|c|c|c|c|c|c|c|c|}
\hline \multirow[b]{2}{*}{ Variable } & \multicolumn{2}{|c|}{ Standard ANOVA } & \multicolumn{5}{|c|}{ Tukey-Kramer HSD Comparisons } & \\
\hline & $\begin{array}{l}\text { Mean } \\
\text { square }\end{array}$ & $\begin{array}{l}\text { Prob } \\
>F\end{array}$ & $\begin{array}{l}\text { Urban } \\
(n=4)\end{array}$ & & $\begin{array}{l}\text { Developing } \\
\quad(n=4)\end{array}$ & & $\begin{array}{c}\text { Rural } \\
(n=4)\end{array}$ & \\
\hline$\%$ Insect incidence for all trees & 4.70 & 0.48 & $2.50 \pm 1.81$ & & $0.33 \pm 0.33$ & & $1.33 \pm 1.03$ & \\
\hline$\%$ Disease incidence for all trees & 14.51 & 0.59 & $4.25 \pm 1.75$ & & $4.00 \pm 4.00$ & & $0.83 \pm 0.63$ & \\
\hline$\%$ Mechanical damage incidence for all trees & 279.90 & 0.09 & $30.25 \pm 2.96$ & (a) & $19.25 \pm 3.18$ & $(a, b)$ & $13.83 \pm 6.96$ & (b) \\
\hline$\%$ Insect + disease + mech damage for all trees & 452.34 & 0.04 & $37.00 \pm 3.82$ & (a) & $23.58 \pm 3.91$ & $(a, b)$ & $16.00 \pm 6.53$ & (b) \\
\hline$\%$ Trees with lichens & 1320.08 & 0.22 & $51.83 \pm 21.46$ & (a) & $74.08 \pm 11.67$ & $(\mathrm{a}, \mathrm{b})$ & $87.83 \pm 5.78$ & (b) \\
\hline Mean number of lichen species per tree & 6.23 & 0.14 & $0.75 \pm 0.43$ & (a) & $2.50 \pm 1.04$ & (b) & $3.17 \pm 0.90$ & (b) \\
\hline Mean lichen abundance rank for all hardwoods & 1.44 & 0.13 & $0.42 \pm 0.16$ & (a) & $1.25 \pm 0.48$ & (b) & $1.58 \pm 0.42$ & (b) \\
\hline Mean number of crustose species on water oaks & 0.90 & 0.68 & $4.61 \pm 0.85$ & & $4.15 \pm 0.66$ & & $5.09 \pm 0.70$ & \\
\hline Mean number of foliose species on water oaks & 1.19 & 0.24 & $1.29 \pm 0.53$ & $(a, b)$ & $0.68 \pm 0.30$ & (a) & $1.77 \pm 0.39$ & (b) \\
\hline Crustose: foliose ratio (on water oaks) & 131.15 & 0.10 & $9.72 \pm 3.65$ & & $15.95 \pm 4.03$ & & $4.52 \pm 1.83$ & \\
\hline Mean lichen abundance rank for water oaks & 91.97 & 0.57 & $26.15 \pm 8.15$ & & $17.50 \pm 4.00$ & & $25.42 \pm 5.66$ & \\
\hline Mean dominance of crustose over foliose & 0.16 & 0.21 & $1.23 \pm 0.18$ & & $1.04 \pm 0.04$ & & $1.44 \pm 0.17$ & \\
\hline
\end{tabular}

${ }^{1} \mathrm{SE}=$ standard error of the mean; $n=$ number of study sites sampled; Mean values in a row with different letters are significantly different $(P<.05)$ based on Tukey-adjusted least squares means.

this analysis. Only percent pasture land cover, distance to nearest road, and percent canopy cover were entered into the model by the mixed stepwise fit procedure. These variables were the best indicators of lichen species richness in West Georgia forests:

$$
\begin{aligned}
y= & -3.20434+0.0459367 \% \text { canopy cover } \\
& +0.0024509 \text { distance to any road } \\
& +24.954566 \% \text { pasture. }
\end{aligned}
$$

Percent pasture land accounted for 31\% of the variance in the data, with distance to nearest road adding another $9 \%$ and percent canopy cover adding another 5\%, for a total estimated $r^{2}$ of 0.45 . Once the standard least squares regression model was run, these estimates proved to be accurate $\left(r^{2}\right.$ of 0.45 , RMSE $\left.=1.43\right)$. Although the $r^{2}$ is relatively low, the results indicate that lichen species richness may be related to percent pasture land, distance to nearest road, and percent canopy cover, but that other unmeasured factors may have also been involved. 
TABLE 4: Standard ANOVA values and means $( \pm$ SE) for urbanization variables collected in "West Georgia".

\begin{tabular}{|c|c|c|c|c|c|c|c|c|}
\hline \multirow[b]{2}{*}{ Variable } & \multicolumn{2}{|c|}{ Standard ANOVA } & \multicolumn{5}{|c|}{ Tukey-Kramer HSD Comparisons } & \\
\hline & $\begin{array}{l}\text { Mean } \\
\text { square }\end{array}$ & $\begin{array}{c}\text { Prob }> \\
\quad F\end{array}$ & $\begin{array}{c}\text { Urban } \\
(n=4)\end{array}$ & & $\begin{array}{l}\text { Developing } \\
\quad(n=4)\end{array}$ & & $\begin{array}{c}\text { Rural } \\
(n=4)\end{array}$ & \\
\hline Population density & 729062 & $<0.01$ & $771.11 \pm 191.73$ & (a) & $51.40 \pm 23.97$ & (b) & $13.37 \pm 1.79$ & (b) \\
\hline Housing density & 119322 & $<0.01$ & $311.32 \pm 79.97$ & (a) & $18.76 \pm 8.12$ & (b) & $5.99 \pm 1.10$ & (b) \\
\hline Road density & 44.86 & $<0.01$ & $7.40 \pm 0.99$ & (a) & $1.77 \pm 0.15$ & (b) & $1.45 \pm 0.10$ & (b) \\
\hline Plot distance to any road $(\mathrm{m})$ & 59371 & 0.20 & $111.58 \pm 9.29$ & & $341.75 \pm 97.68$ & & $295.92 \pm 116.07$ & \\
\hline Plot distance to major road $(\mathrm{m})$ & 25767 & 0.79 & $486.67 \pm 128.18$ & & $378.33 \pm 83.33$ & & $535.08 \pm 236.19$ & \\
\hline$\%$ Forest & 1781 & $<0.01$ & $42.28 \pm 3.20$ & (a) & $79.13 \pm 0.91$ & (b) & $78.51 \pm 2.92$ & (b) \\
\hline$\%$ Pasture & 29.60 & 0.02 & $0.51 \pm 0.17$ & (a) & $3.63 \pm 1.03$ & $(\mathrm{a}, \mathrm{b})$ & $5.93 \pm 1.61$ & (b) \\
\hline$\%$ Grasses (pasture + lawn) & 0.34 & 0.93 & $5.82 \pm 0.87$ & & $5.54 \pm 0.55$ & & $6.12 \pm 1.48$ & \\
\hline$\%$ Urban & 3054 & $<0.01$ & $50.01 \pm 3.22$ & (a) & $4.26 \pm 2.24$ & (b) & $0.29 \pm 0.26$ & (b) \\
\hline$\%$ Nonvegetated (urban + bare ground) & 1762 & $<0.01$ & $50.01 \pm 3.22$ & (a) & $13.72 \pm 0.49$ & (b) & $13.59 \pm 2.02$ & (b) \\
\hline Forest patch density & 223 & $<0.01$ & $14.54 \pm 2.66$ & (a) & $1.85 \pm 0.13$ & (b) & $1.40 \pm 0.33$ & (b) \\
\hline Forest edge density & 7147 & $<0.01$ & $137.66 \pm 8.72$ & (a) & $70.10 \pm 1.90$ & (b) & $59.87 \pm 3.34$ & (b) \\
\hline Forest perimeter-area fractal shape & 0.004 & 0.05 & $1.49 \pm 0.02$ & (a) & $1.45 \pm 0.00$ & (b) & $1.44 \pm 0.01$ & (b) \\
\hline Shannon's landscape diversity index & 0.07 & $<0.01$ & $0.94 \pm 0.01$ & (a) & $0.74 \pm 0.02$ & (b) & $0.70 \pm 0.05$ & (b) \\
\hline Shannon's landscape evenness index & 0.06 & $<0.01$ & $0.68 \pm 0.01$ & (a) & $0.46 \pm 0.01$ & (b) & $0.47 \pm 0.05$ & (b) \\
\hline Maximum seasonal ozone concentration & 9.53 & $<0.01$ & $15.26 \pm 1.95$ & & $11.24 \pm 1.11$ & & $14.73 \pm 0.12$ & \\
\hline Maximum seasonal NO $x$ concentration & 7.44 & 0.02 & $6.03 \pm 0.29$ & (a) & $2.88 \pm 0.47$ & (b) & $2.52 \pm 0.53$ & (b) \\
\hline
\end{tabular}

${ }^{1}$ SE: standard error of the mean. $n$ : number of study sites sampled. Mean values in a row with different letters are significantly different $(P<.05)$ based on Tukey-adjusted least squares means.

TABLE 5: Independent versus dependent variable correlations for lichen prediction models ${ }^{1}$.

\begin{tabular}{|c|c|c|c|c|c|}
\hline \multicolumn{3}{|l|}{ Model 1} & \multicolumn{3}{|l|}{ Model 2} \\
\hline \multicolumn{3}{|l|}{ Dependent variable: percentage of trees with lichens } & \multicolumn{3}{|c|}{ Dependent Variable: number of lichen species per tree } \\
\hline Independent variables: & Rho & $P$ & Independent Variables: & Rho & $P$ \\
\hline$\%$ Peak canopy cover & 0.55 & .07 & Plot distance to any road (m) & 0.57 & .05 \\
\hline Plot distance to any road $(\mathrm{m})$ & 0.34 & .28 & $\%$ Pasture & 0.55 & .06 \\
\hline Mean upper canopy height (m) & -0.64 & .03 & \% Peak canopy cover & 0.55 & .07 \\
\hline Basal area $\left(\mathrm{m}^{2} / \mathrm{ha}\right)$ & -0.53 & .08 & \% Forest & 0.46 & .13 \\
\hline Housing density & -0.48 & .11 & Housing density & -0.61 & .03 \\
\hline Mean $\mathrm{dbh}(\mathrm{cm})$ of all mature trees & -0.20 & .53 & Mean subcanopy height $(\mathrm{m})$ & -0.47 & .12 \\
\hline Forest edge density & -0.27 & .40 & Forest edge density & -0.35 & .26 \\
\hline \multirow[t]{3}{*}{$\%$ Insect + Disease + Mech damage for all trees } & -0.35 & .27 & $\%$ Urban + Bareground & -0.39 & .20 \\
\hline & & & Basal Area $\left(\mathrm{m}^{2} / \mathrm{ha}\right)$ & -0.45 & .14 \\
\hline & & & Mean dbh $(\mathrm{cm})$ of all mature trees & -0.42 & .17 \\
\hline
\end{tabular}

${ }^{1}$ Correlation coefficients (Rho) and $P$-values $(P=$ Prob $>\mid$ Rho $\mid)$ derived using Spearman's Rank multivariate correlation matrix.

\section{Discussion}

The overall goal of this study was to examine the effects of urbanization on forest stand structure and condition along an urban-rural gradient through the use of forest plot characterization data and bioindicators of ecosystem health. More specifically, are there indicators of forest condition that can be modeled, predicted, and used as surrogates for forest health as defined by McLaughlin and Percy [5]?

One of the major purposes of the characterization data was to determine if and how the variables differed among sites. Of the forest stand structure variables measured, only two diverged among land use types. We observed that urban areas contained fewer tree species than either rural or developing sites. Results regarding the urban areas were not unexpected, since these locales typically have been reported to have less tree basal area and decreases in native plant density than rural areas [34-37]. Reports regarding species diversity have been mixed. Burton and Samuelson [17] found in the same "West Georgia" riparian corridors that urban sites contained lower forest cover yet the highest diversity. This was due to a higher richness of nonnative species than the other sites. Our results were somewhat different and probably due to the fact that we only measured tree species $>10 \mathrm{~cm}$ and did not distinguish different shrubs, understory trees, and groundcover by species. 
In our study, developing areas contained the most diverse tree species mix. This may imply that rural areas that are currently under development still have greater native species diversity than long-established urban centers, yet that diversity primarily of native species might tend to decrease as development increases and areas become more urbanized [38].

Tree injury variables measured were overall not significantly different between land use types. Of the four variables measured, only percent incidence of mechanical injury and the combined injury resulting from pests, diseases, and mechanical injury were dissimilar. These results suggest that there were more mechanically injured trees in urban plots (30\% of trees sampled). However, it is interesting that $14 \%$ and $19 \%$ of trees sampled in rural and developing areas, respectively, were also damaged, and might be explained by two back-to-back large-scale disturbances in the "West Georgia" region. On September 16-17, 2004, Hurricane Ivan (a Category 5 hurricane at sea and Category 3 at landfall) traversed through the region, with its high-speed winds toppling and weakening trees and creating gaps in the canopy. This was followed four months later by a major ice storm on January 28-29, 2005. Since these two major disturbances occurred just prior to sampling, it is possible that this is the reason many of the sites, regardless of land use type, had relatively high mechanical injury scores.

Typically, forests that have experienced disturbance are often more susceptible to other forms of environmental stress [6]. Interestingly, symptoms of injury by pests and/or diseases were negligible in our study indicating land use type was not affecting the \% damage from insects and disease. These results are contrary to the findings of previous studies in which urban systems were found to have a higher incidence of pests and diseases [5, 39, 40]. Differences observed between our study and others could be attributed to (1) location and species composition, (2) natural fluctuations in pest and disease cycles resulting in minimal signs or symptoms of activity during the sampling period, (3) the use of pesticides/herbicides that is typical in urban and agricultural areas [39], and (4) it also could be due to rapid harvesting of diseased or pest-infested timber after an outbreak (i.e., southern pine beetle and/or fusiform rust), which is typical in city parks and residential areas. Since our urban plots were generally located in the natural areas of parks or residential areas, the first two factors are the most likely reasons for these differences.

Of all the variables tested, lichens were found to be the most significant indicator of potential changes in forest condition resulting from urbanization. The percentage of lichens on all trees was greater in rural locations followed by developing areas, with the least incidence in the urban plots. Our findings were similar to those of McCune et al. [7] and Geiser and Neitlich [10], who observed far less lichen abundance on trees in urban areas of the Southeastern and Northwestern US, respectively.

More importantly, numbers of lichen species in each of the land use types was different. There was greater lichen species richness in rural and developing regions than in urban areas. Lichen species diversity has also been shown to vary greatly with exposure to air pollutants such as $\mathrm{SO}_{2}$ and $\mathrm{NO}_{2}[10,33,41,42]$. Gombert et al. [28] reported that lichen species diversity was influenced by an increase in "environmental artificiality," or the presence of artificial features typical of urban environments (roads, developments) over natural features across a landscape, in Grenoble, France rather than air pollution exposure alone, with urban areas having lower lichen species diversity than rural areas.

Lichen species richness has been used as an indicator of forest health [7, 43]. Some species may be disappearing from urban forests [7], while those present in urban forests could possibly be nitrophytic, or nitrogen-demanding species [28, 42]. Overall, we found decreases in numbers of species. However, more in-depth taxonomic surveys of the lichen communities present are needed to validate this hypothesis. In a related study, Styers and Chappelka [19] found lichens collected from urban sites contained higher concentrations of $\mathrm{Cu}, \mathrm{N}, \mathrm{Pb}, \mathrm{S}$, and $\mathrm{Zn}$ than all other sites. All of these elements are indicators of higher pollutant loads that are common in urban environments [10]. These results along with those reported in this study indicate that lichens may be a sensitive indicator of land use change.

Using data collected in the field in concert with data collected for various measures of urbanization, regression equations were developed for predicting lichen occurrence and species richness. From the regression modeling of lichen incidence (Model 1), we found that as housing density and upper canopy height decreased, and as forest edge density and $\mathrm{dbh}$ increased, the percentage of trees with lichens increased. High housing densities are typically indicative of urbanized areas [44]. However, we did not conduct measures in the field regarding differences in lichen abundance, richness, and so forth, along forest edges where edge effects which may be important in lichen viability $[31,45]$. More research combining lichen data collection techniques and microclimate measures, for example, light penetration, temperature, and humidity, at various intervals from forest edge to interior are needed.

We also attempted to predict lichen species richness within a given forested stand. As percent pasture land cover, distance to nearest road, and percent canopy cover increased, the number of lichen species per tree also increased. The significance of percent pasture land might suggest two things. First, pasture land tends to fragment the landscape but sometimes a certain amount of forest cover is maintained, especially along riparian areas, however minimal [46]. As such, small forest patches occasionally remain, but these have a higher edge-to-interior ratio $[47,48]$. This may result in a greater number of lichen edge species colonizing the forest patch $[28,31]$. In the absence of pollutant exposure, these lichens might be able to thrive in these edge environments, unlike lichens in urban environments where edge locations would render them more vulnerable to pollution exposure $[28,31]$. Again, however, this study did not measure lichens along forest edges in order to be able to further scrutinize these modeled results.

Distance to nearest road as indicated in the model suggests this could possibly be a factor. Lichen communities located farther away from roads and mobile pollution 
sources tend to be more species rich $[39,49]$. Roads create edges, as do other interruptions in forest cover; however, it may be possible that there is greater mortality of pollutionsensitive edge lichens due to pollutant exposure from vehicular traffic which could mask any increases in lichen species richness resulting from new edges created by roads [49].

As percent forest canopy increased, so did species richness. These predictions would support our findings regarding more species diversity in rural versus urban areas. Our analysis suggests that patches with a greater amount of canopy cover appear to have a greater number of lichen species. However, more in-depth canopy density measurements and throughfall assessments should be conducted to confirm the results.

\section{Conclusions}

These results indicate subtle differences in forest structure and condition across land use types in "West Georgia." Of the variables measured to determine changes in stand structure, only two differed among land use types. We observed that urban areas contained fewer tree species than either rural or developing sites. Changes among land use types were not observed for pests or diseases, but we observed a greater incidence of mechanical injury in the urban sites. This may have resulted from more stress in these areas, or simply could have been due to random chance. The best indicators of potential changes in forest condition were changes in lichen communities. Lichen incidence, abundance, and species richness were the greatest in rural forests and the least in urban locations. Lichens are very sensitive to environmental stressors. Our data indicate relationships between lichens and urbanization variables such as housing density and forest edge density were present. These results support the assumption that these ecosystems may be responding to landscape change.

It was expected that indicators of forest condition in urban versus rural areas would have been much more distinct. This might have been the case if more plots been selected for sampling, had there been a greater number of sites in each of the land use types, or if sampling had occurred over a broader spatial extent. Quite possibly, the developing sites selected may have been more indicative of rural land use types, given the low values of the various urbanization variables calculated (e.g., housing density, forest cover). The selection of new sampling sites in developing areas of more intermediate "urbanized" values might improve these analyses, since the ranges between developing and urban area values in several of the measured variables were great. Regardless, the results obtained suggest that there are subtle differences in several of the forest health variables measured, specifically those of lichens. The differences observed could possibly be related to increases in pollution load and greater forest fragmentation in the urban locales, resulting from rapid increases in urbanization in the Columbus area. Our study was ambitious in nature and provides data that support the hypothesis that these ecosystems may be changing as a function of rapid urbanization. By refining our methods and adding more sampling plots, more distinct results may be obtained from this type of assessment.

\section{Acknowledgments}

Funding for this project was provided by Auburn University's Center for Forest Sustainability. The authors wish to thank Luke Marzen, Graeme Lockaby, and Wayne Zipperer and two anonymous reviewers for reading an earlier version of the manuscript. The author wishes to thank Efrem Robbins, Kyle Marable, Justin Stringfellow, Zoltan Szantoi, Curtis Hansen, Kevin Kleiner, and Tanka Acharya for assistance in data collection and analysis. Additional thanks are given to Columbus Parks and Recreation, The Preserve at Callaway Gardens, Joe Kurz Wildlife Management Area, and other private landowners for property access permission.

\section{References}

[1] M. J. Mcdonell, S. T. A. Picket, P. Groffman et al., "Ecosystem processes along an urban-to-rural gradient," Urban Ecosystems, vol. 1, pp. 21-36, 1997.

[2] R. A. Erickson, "The evolution of the suburban space economy," Urban Geography, vol. 4, no. 2, pp. 95-121, 1983.

[3] T. A. Hartshorn, "Cities: turning the suburbs inside out," in Proceedings of the 99th Annual Meeting of the Association of American Geographers, New Orleans, La, USA, March 2003.

[4] D. N. Wear and J. G. Greis, "Southern forest resource assessment," General Technical Report. SRS-53., U.S. Department of Agriculture, Forest Service, Southern Research Station, Portland, Ore, USA, 2002.

[5] S. McLaughlin and k. Percy, "Forest Health in North America: some perspectives on actual and potential roles of climate and air pollution," Water, Air and Soil Pollution, vol. 116, pp. 151$197,1999$.

[6] W. C. Zipperer, "Species composition and structure of regenerated and remnant forest patches within an urban landscape," Urban Ecosystems, vol. 6, pp. 271-290, 2002.

[7] B. McCune, J. Dey, J. Peck et al., "Regional gradients in lichen communities of the Southeast United States," The Byrologist, vol. 100, pp. 145-158, 1997.

[8] D. J. Nowak, J. E. Pasek, R. Sequeira et al., "Potential effect of anoplophora glabripennis(coleoptera: cerambycidae)on urban trees in the United States," Journal of Economic Entomology, vol. 94, pp. 116-122, 2001.

[9] D. J. Nowak and J. R. McBride, "Comparison of monterey pine stress in urban and natural forests," Journal of Environmental Management, vol. 32, pp. 383-395, 1991.

[10] L. H. Geiser and P. N. Neitlich, "Air pollution and climate gradients in western Oregon and Washington indicated by epiphytic macrolichens ," Environmental Pollution, vol. 145, no. 3, pp. 203-218, 2007.

[11] R. Parsons, "Conflict between ecological sustainability and environmental aesthetics: conundrum, canard or curiosity," Landscape and Urban Planning, vol. 32, pp. 227-244, 1995.

[12] T. C. Daniel, "Whither scenic beauty? visual landscape quality assessment in the 21st century," Landscape and Urban Planning, vol. 54, no. 1-4, pp. 267-281, 2001.

[13] R. Parsons and T. C. Daniel, "Good looking: in defense of scenic landscape aesthetics," Landscape and Urban Planning, vol. 60 , no. 1, pp. 43-56, 2002. 
[14] M. J. McDonnell and S. T. A. Pickett, "Ecosystem structure and function along urban-rural gradients: an unexploited opportunity for ecology," Ecology, vol. 71, no. 4, pp. 1232-1237, 1990.

[15] B. G. Lockaby, D. Zhang, J. McDaniel, H. Tian, and S. Pan, "Interdisciplinary research at the Urban-rural interface: the WestGa project," Urban Ecosystems, vol. 8, no. 1, pp. 7-21, 2005.

[16] M. J. McDonnell, S. T. A. Pickett, and R. V. Pouyat, "The application of the ecological gradient paradigm to the study of urban effects," in Humans as Components of Ecosystems: Subtle Human Effects and the Ecology of Populated Areas, M. J. McDonnell, S. T. A. Pickett STA et al., Eds., Springer, New York, NY, USA, 1993.

[17] M. L. Burton and L. J. Samuelson, "Influence of urbanization on riparian forest diversity and structure in the Georgia Piedmont, US," Plant Ecology, vol. 195, no. 1, pp. 99-115, 2008.

[18] D. M. Styers, "Urban sprawl and atmospheric pollution effects on forests in the Georgia Piedmont," in Doctoral Dissertation, School of Forestry \& Wildlife Sciences, Auburn University, Auburn, Alabama, 2008.

[19] D. M. Styers and A. H. Chappelka, "Urbanization and atmospheric deposition: using bioindicators of determining patterns of land use change in West Georgia," Water, Air, and Soil Pollution, vol. 200, no. 1-4, pp. 371-386, 2009.

[20] D. M. Styers, A. H. Chappelka, L. J. Marzen, and G. L. Somers, "Developing a land-cover classification to select indicators of forest ecosystem health in a rapidly urbanizing landscape," Landscape and Urban Planning, vol. 94, no. 3-4, pp. 158-165, 2010.

[21] D. M. Styers, A. H. Chappelka, L. J. Marzen, and G. L. Somers, "Scale matters: indicators of ecological health along the urbanrural interface near Columbus, Georgia," Ecological Indicators, vol. 10, no. 2, pp. 224-233, 2010.

[22] D. G. Brown, K. M. Johnson, T. R. Loveland, and D. M. Theobald, "Rural land-use trends in the conterminous United States, 1950-2000,” Ecological Applications, vol. 15, no. 6, pp. 1851-1863, 2005.

[23] U.S. Census Bureau Census 2000 Geographic Definitions, 2001, http://www.census.gov/geo/www/geo_defn.html\#UR.

[24] USDA Forest Service FIA Field Methods for Phase 3 Measurements, 2006, http://fia.fs.fed.us/library/field-guidesmethods-proc/.

[25] J. E. Schoonover, B. G. Lockaby, and B. Helms, "Impacts of land cover on stream hydrology in the West Georgia Piedmont, USA," Journal of Environmental Quality, vol. 35, no. 6, pp. 2123-2131, 2006.

[26] T. H. Nash and C. Gries, "Lichens as indicators of air pollution," in Air Pollution, O. Hutzinger, Ed., Springer, New York, NY,USA, 1986.

[27] B. McCune, "Lichen communities as indicators of forest health," The Bryologist, vol. 103, no. 2, pp. 353-356, 2000.

[28] S. Gombert, J. Asta, and M. R. D. Seaward, "Assessment of lichen diversity by index of atmospheric purity (IAP), index of human impact (IHI) and other environmental factors in an urban area(Grenoble, southeast France)," Science of the Total Environment, vol. 324, no. 1-3, pp. 183-199, 2004.

[29] M. c. Garigal, M. Kevin, and J. Barbara, "FRAGSTATS: spatial pattern analysis program for quantifying landscape structure," General Technical Report PNW-GTR-351, U.S.Department of Agriculture, Forest Service, Pacific Northwest Research Station, Portland, Ore, USA, 1995.
[30] SAS Institute Inc, JMP IN@, Version 5.1.2., SAS Institute Inc, Cary, NC, USA, 2003.

[31] P. Esseen and K. Renhorn, "Edge effects on an epiphytic lichen in fragmented forests," Conservation Biology, vol. 12, no. 6, pp. 1307-1317, 1998.

[32] J. M. Kalwij, H. H. Wagner, and C. Scheidegger, "Effects of stand-level disturbances on the spatial distribution of a lichen indicator," Ecological Applications, vol. 15, no. 6, pp. 20152024, 2005.

[33] L. Frati, E. Caprasecca, S. Santoni et al., "Effects of NO2 and NH3 from road traffic on epiphytic lichens," Environmental Pollution, vol. 142, no. 1, pp. 58-64, 2006.

[34] E. E. Porter, B. R. Forschner, and R. B. Blair, "Woody vegetation and canopy fragmentation along a forest-to-urban gradient," Urban Ecosystems, vol. 5, pp. 131-151, 2001.

[35] M. L. McKinney, "Urbanization, biodiversity, and conservation," Conservation Biology, vol. 52, no. 10, pp. 883-890, 2002.

[36] S. F. Moffatt, S. M. McLachlan, and N. C. Kenkel, "Impacts of land use on riparian forest along an urban-rural gradient in southern Manitoba," Plant Ecology, vol. 174, no. 1, pp. 119135, 2004.

[37] M. L. Burton, L. J. Samuelson, and S. Pan, "Riparian woody plant diversity and forest structure along an urbanrural gradient," Urban Ecosystems, vol. 8, no. 1, pp. 93-106, 2005.

[38] J. R. Miller and R. J. Hobbs, "Conservation where people live and work," Conservation Biology, vol. 16, no. 2, pp. 330-337, 2002.

[39] N. E. McIntyre, "Ecology of urban arthropods: a review and a call to action," Annals of the Entomological Society of America, vol. 93, no. 4, pp. 825-835, 2000.

[40] M. L. McKinney, "Urbanization as a major cause of biotic homogenization," Biological Conservation, vol. 127, pp. 247260, 2006.

[41] H. F. Van Dobben, H. T. Wolterbeek, G. W. W. Wamelink, and C. J. F. Ter Braak, "Relationship between epiphytic lichens, trace elements and gaseous atmospheric pollutants," Environmental Pollution, vol. 112, no. 2, pp. 163-169, 2001.

[42] M. E. Fenn, L. Geiser, R. Bachman, T. J. Blubaugh, and A. Bytnerowicz, "Atmospheric deposition inputs and effects on lichen chemistry and indicator species in the Columbia River Gorge, USA," Environmental Pollution, vol. 146, no. 1, pp. 7791, 2007.

[43] P. S. Muir and B. McCune, "Lichens, tree growth, and foliar symptoms of air pollution: are the stories consistent?" Journal of Environmental Quality, vol. 17, no. 3, pp. 361-370, 1988.

[44] US Census Bureau, "Topologically integrated geographic encoding and referencing system(TIGER®)," September 2006, http://www.census.gov/geo/www/tiger/.

[45] S. C. Sillett, "Growth rates of two epiphytic cyanolichen species at the edge and in the interior of a 700-year-old douglas fir forest in the western cascades of oregon," The Bryologist, vol. 97, no. 3, pp. 321-324, 1994.

[46] W. S. Platts, "Methods for evaluating riparian habitats with application to management," General Technical Report INT221, US Department of Agriculture, Forest Service, Intermountain Research Station, 1987.

[47] W. C. Zipperer, R. L. Burgess, and R. D. Nyland, "Patterns of deforestation and reforestation in different landscape types in central New York," Forest Ecology and Management, vol. 36, no. 1, pp. 103-117, 1990. 
[48] W. C. Zipperer, "Deforestation patterns and their effects on forest patches," Landscape Ecology, vol. 8, no. 3, pp. 177-184, 1993.

[49] J. N. Cape, Y. S. Tang, N. Van Dijk, L. Love, M. A. Sutton, and S. C. F. Palmer, "Concentrations of ammonia and nitrogen dioxide at roadside verges, and their contribution to nitrogen deposition," Environmental Pollution, vol. 132, no. 3, pp. 469478, 2004. 

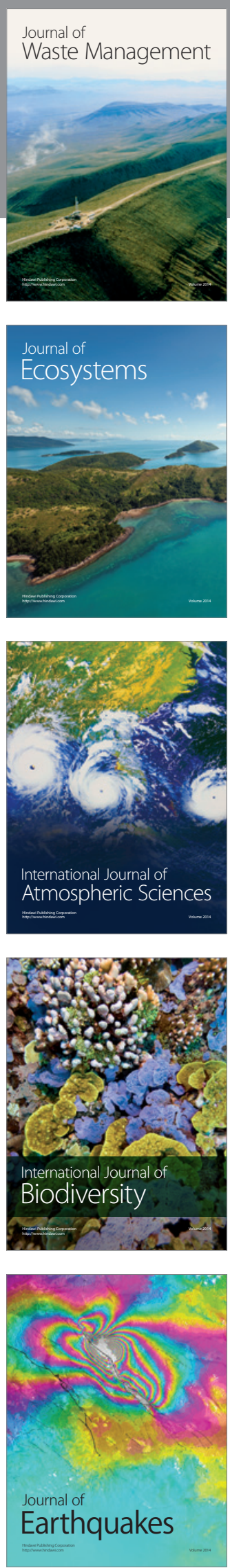
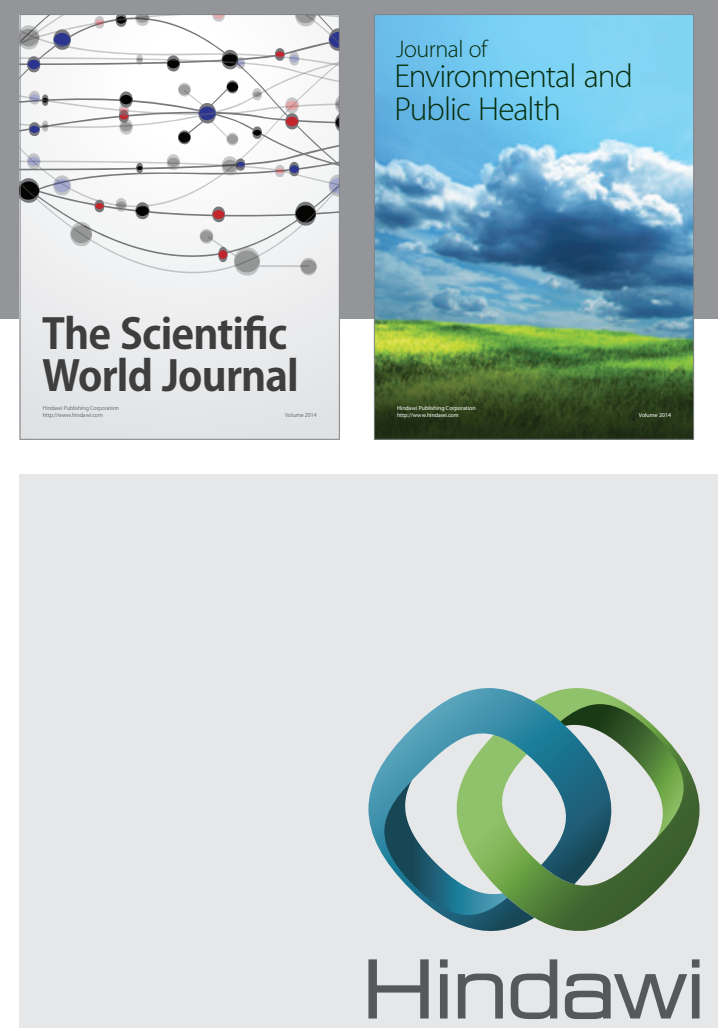

Submit your manuscripts at

http://www.hindawi.com
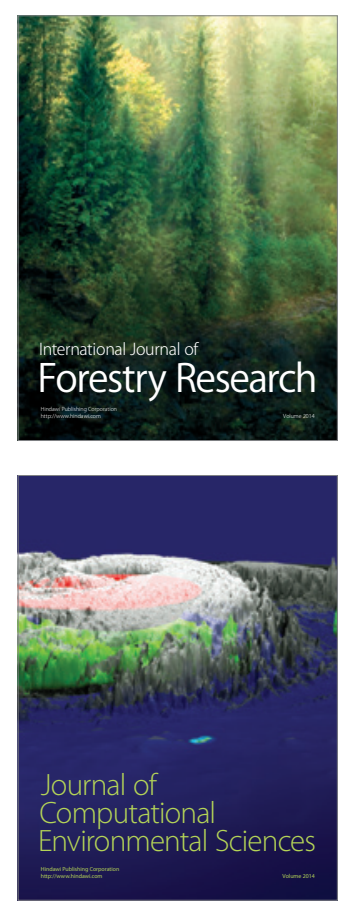
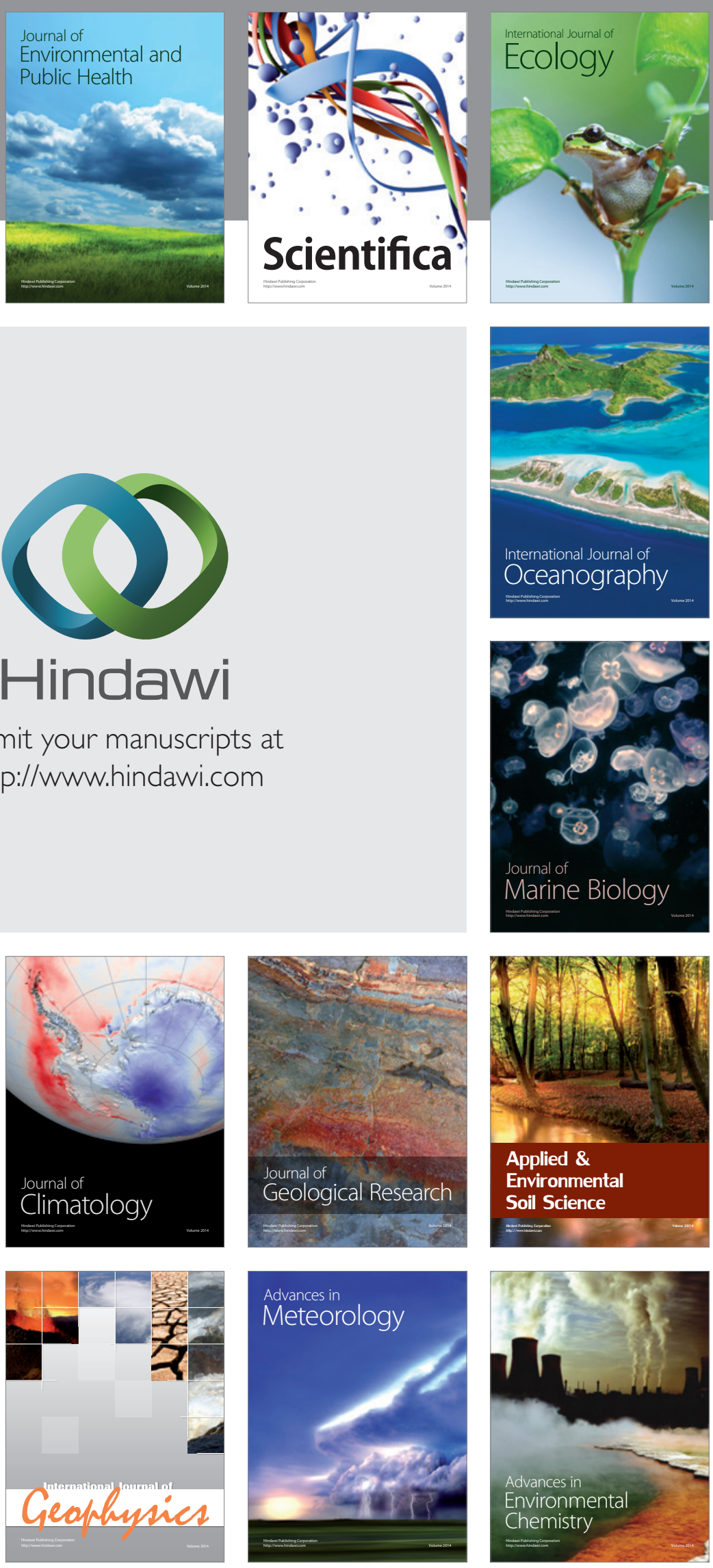